\title{
DE JAGUNÇO A MATRAGA
}

\author{
Bianca Meira Lopes
}

Submetido em 28 de maio de 2018.

Aceito para publicação em 20 de setembro de 2018.

Cadernos do IL, Porto Alegre, n. ${ }^{\circ}$ 57, novembro, p. 90-100

\section{POLÍTICA DE DIREITO AUTORAL}

Autores que publicam nesta revista concordam com os seguintes termos:

(a) Os autores mantêm os direitos autorais e concedem à revista o direito de primeira publicação, com o trabalho simultaneamente licenciado sob a Creative Commons Attribution License, permitindo o compartilhamento do trabalho com reconhecimento da autoria do trabalho e publicação inicial nesta revista.

(b) Os autores têm autorização para assumir contratos adicionais separadamente, para distribuição não exclusiva da versão do trabalho publicada nesta revista (ex.: publicar em repositório institucional ou como capítulo de livro), com reconhecimento de autoria e publicação inicial nesta revista.

(c) Os autores têm permissão e são estimulados a publicar e distribuir seu trabalho online (ex.: em repositórios institucionais ou na sua página pessoal) a qualquer ponto antes ou durante o processo editorial, já que isso pode gerar alterações produtivas, bem como aumentar o impacto e a citação do trabalho publicado.

(d) Os autores estão conscientes de que a revista não se responsabiliza pela solicitação ou pelo pagamento de direitos autorais referentes às imagens incorporadas ao artigo. A obtenção de autorização para a publicação de imagens, de autoria do próprio autor do artigo ou de terceiros, é de responsabilidade do autor. Por esta razão, para todos os artigos que contenham imagens, o autor deve ter uma autorização do uso da imagem, sem qualquer ônus financeiro para os Cadernos do IL.

\section{POLÍTICA DE ACESSO LIVRE}

Esta revista oferece acesso livre imediato ao seu conteúdo, seguindo o princípio de que disponibilizar gratuitamente o conhecimento científico ao público proporciona sua democratização.

http://seer.ufrgs.br/cadernosdoil/index

Quinta-feira, 22 de novembro de 2018. 


\title{
DE JAGUNÇO A MATRAGA
}

\section{FROM A FUGITIVE GUNSLINGER TO MATRAGA}

\author{
Bianca Meira Lopes ${ }^{25}$
}

\begin{abstract}
RESUMO: O presente estudo propõe uma reflexão filosófica ao conto "A hora e a vez de Augusto Matraga”, escrito por Guimarães Rosa em 1946. Tendo como objetivo chegar a uma conclusão de quem é de fato "Matraga", através da análise de todo o processo de transformação do protagonista, o trabalho tem como base os conceitos de Corpo sem Órgãos, rostidade e devir, desenvolvidos por Deleuze e Guatarri. As contribuições dos autores ajudarão na compreensão do ser como múltiplo, que está sempre se conectando com o mundo, e assim, sempre se transformando, temática amplamente abordada na narrativa Rosiana.
\end{abstract}

PALAVRAS-CHAVE: Matraga; Corpo sem Órgãos; Rostidade; Devir.

ABSTRACT: This study proposes a philosophical reflection on the short story "The hour and turn of Augusto Matraga" written by Guimarães Rosa in 1946. It aims to reach a conclusion as to who actually "Matraga" is through analysis of the entire transformation process of the protagonist. This paper is based on the concepts of Body without Organs, faciality and future which were developed by Deleuze and Guatarri. The contributions of the authors will help in the understanding of how multiple the individual can be by keeping touch with the world frequently, and so, always going through changes. That is widely addressed in Guimarães Rosa's narrative

KEYWORDS: Matraga; Body without Organs; faciality; Future.

RESUMEN: El presente estudio propone uma reflexión filosófica al cuento "A hora e a vez de Augusto Matraga”, escrito por Guimarães Rosa en 1946. Teniendo como objetivo llegar a una conclusión de quién es realmente "Matraga", a través del análisis de todo el proceso de transformación del protagonista, el trabajo se fundamenta en los conceptos de Cuerpo sin Órganos, rostidad y devir, desarrollados por Deleuze y Guatarri. Las contribuciones de los autores ayudarán en la comprensión del ser como múltiplo, que está siempre conectandose con el mundo, y así, siempre transformandose, temática ampliamente abordada en la narrativa Rosiana.

PALABRAS-CLAVE: Matraga; Cuerpo sin Órganos; Rostidad; Devir.

\section{Considerações iniciais}

Muito se tem dito sobre a temática da transformação na obra de Guimarães Rosa, grande escritor brasileiro que coloca em xeque "o ser" e suas subjetividades. O personagem Riobaldo de Grande Sertão: Veredas e o sobrinho da onça do conto "Meu tio o Iauaretê" são exemplos disto, o que afirmam o caráter filosófico dos textos do autor.

Quanto a este trabalho, pretende-se realizar a análise de um dos contos mais famosos de Rosa, "A hora e a vez de Augusto Matraga", publicado em 1946, no volume de contos Sagarana. O estudo se baseará nos conceitos de Corpo sem Órgãos, rostidade e devir, abordados pelos teóricos Deleuze e Guatarri, nas compilações de textos de $\mathrm{Mil}$ Platôs - capitalismo e esquizofrenia, volume I e III. Os filósofos contribuem para o

\footnotetext{
${ }^{25}$ Mestranda em Estudos em Linguagem na Universidade Estadual de Ponta Grossa (UEPG).
} 
entendimento do ser como múltiplo, em transformação contínua e jamais estática, de essência única.

Pensar o indivíduo como alguém que está constantemente fazendo rizoma é imprescindível para compreender as modificações exercidas pelo protagonista da narrativa que será analisada, uma vez que ele só consegue iniciar seu processo de devir, de tentar criar para si um Corpo sem Órgãos e de desfazer seu rosto quando decide se conectar com o mundo a fora, já que sem isso não seria possível tanta mudança. A transformação de Augusto Matraga é um processo longo, que exige dele muita dedicação para desfazer as normas pelas quais viveu grande parte de sua vida. Sendo assim, analisaremos o ser em devir.

Veremos que o próprio nome do personagem muda de acordo com as modificações de si como pessoa, seus desejos, seus ideais, ou seja, ele muda juntamente com seu nome, cujo vocábulo carrega importante sentido para a compreensão de Augusto como homem. Para iniciarmos a análise do conto, vamos primeiramente à questão do nome do protagonista, cuja pergunta, que é subtítulo do próximo tópico, será retomada no final do estudo.

\section{Quem é matraga?}

"Matraga não é Matraga, não é nada." (ROSA, 2015, p. 298). Eis as palavras inicias do conto "A hora e a vez de Augusto Matraga", que já leva o leitor a se perguntar: quem é então Matraga? Este nome remete a um indivíduo que têm tantos referenciais, mas que, no entanto, segundo o narrador, não é nada. Ele é "Augusto Estêves, filho do Coronel Afonsão Estêves, das Pindaíbas e do Saco-da-Embira. Ou Nhô Augusto - o homem - nessa noitinha de novena, num leilão atrás da igreja, no arraial da Virgem Nossa Senhora das Dores do Córrego do Murici." (ROSA, 2015, p. 298).

No início de sua trajetória, o protagonista é um homem que mantém a aparência de valentão, de dono do lugarejo, onde se destaca sua "homência". É um ser que obedece apenas a seus instintos internos e não compartilha conexões com o mundo a sua volta, o que faz com que aja com violência, estando, assim, enquadrado em uma linha dura, como diriam Deleuze e Guatarri. Movido pelo desejo de briga e pelas regras do sertão, ele não reflete antes de fazer o mal.

Para pensarmos nessa aparência e personalidade que Augusto Matraga exerce no começo de sua história, recorremos a Deleuze e Guatarri para compreendermos a importância que a figura de uma pessoa pode representar. A rostidade, conceito criado pelos filósofos, "é uma produção social do rosto" (DELEUZE \& GUATARRI, 1996, p. 49). Além disso, "O rosto não é um invólucro exterior àquele que fala, que pensa ou que sente.”. (DELEUZE \& GUATARRI, 1996, p.32). Refletindo sobre a máquina abstrata que produz rostos, ou mesmo, a máquina de rostidade, Matraga representa o rosto do sertanejo patriarcalista, criado em um ambiente onde o que vigora é a lei do mais forte. O personagem é o estereótipo de homem que manda na casa e na família, além de ter grande entusiasmo em andar atrás de mulheres e jogos.

Duro, doido e sem detença, como um bicho grande do mato. E, em casa, sempre fechado em si. Nem com a menina se importava. Dela, Dionóra, gostava, às vezes; da sua boca, das suas carnes. Só. No mais, sempre com os capangas, com mulheres perdidas, com o que houvesse de pior. Na fazenda - no Saco-da-Embira, nas Pindaíbas, ou no retiro do Morro Azul - ele tinha outros prazeres, outras mulheres, o jogo do truque e as caçadas. E sem 
efeito eram sempre as orações e promessas, com que ela o pretendera trazer, pelo menos, até a meio caminho direito. (ROSA, 2015, p. 303).

Comparado a "um bicho grande do mato", nota-se que o personagem não se importava com a vida familiar, o que lhe cabia era mandar e desmandar na mulher, na filha e em seus capangas, além de agir com poderio pelo povoado. No entanto, essa rostidade não se sustenta por muito tempo.

Com dívidas grandes, Nhô Augusto ia se enfraquecendo e perdendo tudo o que tinha, a ponto de ver até seus capangas se mudarem para o lado do Major Consilva, seu rival. Porém, para o protagonista o importante era não perder sua honra, lei do sertão que o faz cair em desgraça, já que indo afirmar sua "homência", ao prestar contas com o Major, ele acaba levando uma surra de seus próprios ex-capangas. Depois de o marcarem a ferro, Nhô Augusto pula de um penhasco, mas não morre, ao contrário do que todos pensam. Quase morto, ele é encontrado por um casal de pretos, que passam a cuidar dele. Ao estar se recuperando, com todo o sofrimento por conta das dores físicas, ele percebe quanta maldade fez aos outros: "- Se eu pudesse ao menos ter absolvição dos meus pecados!...”. (ROSA, 2015, p. 311). Com isso, ele desfaz seu rosto de valentão, passando a ser um pecador em remissão que busca apenas o perdão divino: "- Mas, será que Deus vai ter pena de mim, com tanta ruindade que fiz, e tendo nas costas tanto pecado mortal?!" (ROSA, 2015, p. 311). Nesse novo momento de sua vida, o novo homem passa a sentir até mesmo saudade de sua esposa e filha, além de uma tristeza imensa. Mas ele decide não desistir de viver.

Vendo seu sofrimento, o casal que cuidava de Augusto Matraga chama um padre. O religioso diz que ele deveria trabalhar em dobro e fazer o bem para que Deus o perdoasse e assim, o pecador passa a viver para isso, seguindo uma rotina cristã através da ajuda para com os outros, da castidade e das rezas. Segundo Oliveira, "A vinda do padre para fazer-lhe o sermão é como o batismo da criança que, a partir desse momento, passa a existir perante Deus e pode contar com ele." (OLIVEIRA, 2003, p. 111). É como se antes Nhô Augusto não conhecesse a Deus e suas leis e agora que conhece, tem que as cumprir.

O padre diz ao protagonista uma frase de grande importância, a qual este remói durante toda a narrativa: "Cada um tem a sua hora e a sua vez: você há de ter a sua." (ROSA, 2015, p. 312). Existindo diante de Deus e passando a crer que chegará sua hora e vez, Augusto Matraga parte com o casal de pretos para o Tombador, povoado onde tinha uma casa. Lá ele passa a viver sem a força dominante da "homência", renunciando a vida errada que levava antes de sua queda do penhasco. O que o personagem busca é tentar desfazer seu corpo e alcançar o reino dos céus através da atividade do bem, vivendo em um constante devir. Mas para isso é necessário que Augusto Matraga desfaça seu organismo e desfixe os pontos de subjetivação e realidade dominante, que em seu caso, representam a lei do sertão, sua "homência", sua maldade.

O protagonista passa a renunciar ao que antes o dominava, como as mulheres, os jogos e as brigas. De acordo com Oliveira, "A Hora e a vez é a síntese do desejo". (OLIVEIRA, 2003, p. 111), é o que move o personagem a partir da prenuncia do padre. Com isso, Augusto Estêves começa a se conectar com o mundo à sua volta, olhar para o que antes passava despercebido e a viver em uma linha de fuga.

Não convivendo mais com os segmentos que antes o prendiam em seu mundo próprio, Augusto pode tentar criar para si um $\mathrm{CsO}^{26}$. De acordo com Deleuze e Guatarri, jamais se chega a um $\mathrm{CsO}$, passa-se o tempo apenas indo em direção a ele, sem, no entanto, alcançá-lo, isso porque "Não é uma noção, um conceito, mas antes uma prática,

\footnotetext{
${ }^{26}$ Abreviação para Corpo sem Órgãos, presente na teoria de Deleuze e Guatarri.
} 
um conjunto de práticas." (DELEUZE \& GUATARRI, 1996, p. 9). No caso de Matraga, isso se resume às suas atividades cristãs, toda a mudança que ele sofre a partir do momento em que resolve converter-se, e seu sofrimento é parte integrante de sua criação de um Corpo sem Órgãos. Para os teóricos aqui discutidos, já estamos sobre ele, "É sobre ele que dormimos, velamos, que lutamos, lutamos e somos vencidos, que procuramos nosso lugar, que descobrimos nossas felicidades inauditas e nossas quedas fabulosas, que penetramos e somos penetrados, que amamos." (DELEUZE \& GUATARRI, 1996, p. 10). Sendo assim, estamos a todo o momento desfazendo nosso organismo, nossas normas, como faz Matraga, afinal, feliz é aquele que busca fazer para si um Corpo sem Órgãos, pois ele "é uma questão de vida ou de morte, de juventude e de velhice, de tristeza e de alegria. E aí que tudo se decide." (DELEUZE \& GUATARRI, 1996, p. 9).

O corpo é um organismo que contém vários órgãos, vários nomes e lugares específicos. Para criar um CsO é necessário remanejar tudo isso, a ponto de desfazer a forma dominante da instituição organismo, pois é a maneira organizada deste, que é inimiga do CsO. (DELEUZE \& GUATARRI, 1996, p. 21). Voltando ao conto "A hora e a vez de Augusto Matraga", o organismo todo organizado do protagonista era o de sertanejo valentão que tinha seus capangas e é esta instituição que ele tem de desfazer, a fim de alcançar o perdão de Deus, sacrificando-se em trabalhar para os outros sem receber nada em troca, rezando constantemente e deixando de lado seus vícios.

Desfazendo seu Corpo sem Órgãos enquanto morava no povoado do Tombador, onde era sua nova casa, Nhô Augusto desfaz seu segundo rosto, o de pecador em redenção, e passa a adquirir um rosto de santo, ou "meio doido e meio santo" (ROSA, 2015, p. 313).

Trabalhava que nem um afadigado por dinheiro, mas, no feito, não tinha nenhuma ganância e nem se importava com acrescentes: o que vivia era querendo ajudar os outros. Capinava para si e para os vizinhos do seu fogo, no querer de repartir, dando de amor o que possuísse. E só pedia, pois, serviço para fazer, e pouca ou nenhuma conversa.

$\mathrm{O}$ casal de pretos, que moravam junto com ele, era quem mandava e desmandava na casa, não trabalhando um nada e vivendo no estadão. Mas, ele, tinham-no visto mourejar até dentro da noite de Deus, quando havia luar claro. (ROSA, 2015, p. 313 - 314).

O homem que antes tinha fazendas, capangas, que mandava na mulher e era autoritário, agora não tem nem ao menos a ganância de ganhar dinheiro através de seu trabalho, o que queria era apenas ajudar aos outros e rezar, tarefa realmente de um santo. Os valores que antes faziam parte de sua vida foram todos invertidos, do mal para o bem.

\footnotetext{
Nos domingos, tinha o seu gosto de tomar descanso: batendo mato, o dia inteiro, sem sossego, sem espingarda nenhuma e nem nenhuma arma para caçar; e, de tardinha, fazendo parte com as velhas corocas que rezavam o terço ou os meses dos santos. Mas fugia às léguas de viola ou sanfona, ou de qualquer outra qualidade de música que escuma tristezas no coração.

Quase sempre estava conversando sozinho, e isso também era de maluco, diziam; porque eles ignoravam que o que fazia era apenas repetir, sempre que achava preciso, a fala final do padre: - "Cada um tem a sua hora e a sua vez: você há-de ter a sua”. — E era só. (ROSA, 2015, p. 313 -314).
}

Mantendo distância de tudo que o remetia ao vício e à tristeza, Augusto Matraga estava firme em sua tarefa de fazer o bem e esperar sua hora e vez. Apesar das tentações que às vezes o aludiam, ele desfaz seu corpo e rosto de sertanejo valentão. Para 
Deleuze e Guatarri, "Desfazer o rosto é o mesmo que atravessar o muro do significante, sair do buraco negro da subjetividade.” (DELEUZE \& GUATARRI, 1996, p. 58). Deste modo, desfazer o rosto é também um devir.

Mas cada traço liberado de rostidade faz rizoma com um traço liberado de paisageidade, de picturalidade, de musicalidade: não uma coleção de objetos parciais, mas um bloco vivo, uma conexão de hastes na qual os traços de um rosto entram em uma multiplicidade real, em um diagrama, com um traço de paisagem desconhecido, um traço de pintura ou de música que se encontram então efetivamente produzidos, criados, segundo quanta de desterritorialização positiva absoluta, e não mais evocados nem lembrados segundo sistemas de reterritorialização. (DELEUZE \& GUATARRI, 1996, p. $61)$.

Desfazer o rosto é também uma contaminação. Ao perder aspectos de rostidade, apreendem-se outros através do rizoma, das conexões que se criam com outras multiplicidades. Tudo se define pelo fora ou mesmo, pela desterritorialização, fenômeno sofrido por Augusto Matraga, já que ele não compartilha mais do rosto dos que têm "homência". Neste ponto, podemos fazer a relação com o conceito de devir, que não é imitação, como reforçam Deleuze e Guatarri e que além do mais, remete à rostidade. Vejamos o que os teóricos dizem sobre o termo:

[...] captura de código, mais-valia de código, aumento de valência, verdadeiro devir, devir-vespa da orquídea, devir-orquídea da vespa, cada um destes devires assegurando a desterritorialização de um dos termos e a reterritorialização do outro, os dois devires se encadeando e se revezando segundo uma circulação de intensidades que empurra a desterritorialização cada vez mais longe. Não há imitação nem semelhança, mas explosão de duas séries heterogêneas na linha de fuga composta de um rizoma comum que não pode mais ser atribuído, nem submetido ao que quer que seja de significante. Rémy Chauvin diz muito bem: "Evolução a-paralela de dois seres que não têm absolutamente nada a ver um com o outro." (DELEUZE \& GUATARRI, 1996, p. 19).

Em 'A hora e a vez de Augusto Matraga', o protagonista, desterritorializado, não tem mais suas fazendas, sua "homência" e nem mesmo vive a partir da lei violenta do sertão, no entanto, se reterritorializa em um ambiente totalmente diferente, onde reza, faz penitencia e vive para fazer o bem e pagar seus pecados. Aqui podemos fazer a relação com a "Evolução a-paralela", já que um sertanejo valentão não tem nada a ver com um pecador em remissão e santo. Ou seja, é um devir, uma contaminação, que acontece através de seres totalmente diferentes, sem nenhuma semelhança. É uma série que "explode na outra, cria circuito com outra: aumento de potência ou circuito de intensidades." (DELEUZE \& GUATARRI, 1996, p. 17).

Mas como criar um Corpo sem Órgãos não é destruir, apenas reorganizar de forma positiva o organismo, o rosto de santo de Augusto Matraga tem seus altos e baixos. Ele não esquece por completo seu rosto de sertanejo patriarcalista, chefe de família, e por isso, muitas vezes a tristeza toma conta de si, como acontece quando Tião da Thereza traz notícias de sua esposa e filha.

Dona Dionóra, continuava amigada com seu Ovídio, muito de bem os dois, com tenção até em casamento de igreja, por pensarem que ela estava desimpedida de marido; com a filha, sim, é que fora uma tristeza: crescera sã e se encorpara uma mocinha muito linda, mas tinha caído na vida, seduzida por um cometa, que a levara do arraial, para onde não se sabia... O Major Consilva prosseguia mandando no Murici, e arrematara as duas fazendas de Nhô Augusto... Mas o mais mal-arrumado tinha sido com o Quim, seu antigo 
camarada, o pobre do Quim Recadeiro — "Se alembra?" - Pois o Quim tinha morrido de morte-matada, com mais de vinte balas no corpo, por causa dele, Nhô Augusto: quando soube que seu patrão tinha sido assassinado, de mando do Major, não tivera dúvida: ...jurou desforra, beijando a garrucha, e não esperou café coado! Foi cuspir no canguçu detrás da moita, e ficou morto, mas já dentro da sala-de-jantar do Major, e depois de matar dois capangas e ferir mais um... (ROSA, 2015, p. 315).

Ao ouvir o relato de Tião da Thereza, Nhô Augusto fica balançado, mas como tem a fé de que chegará sua hora e vez, segura seus impulsos que antes o dominavam. Neste ponto, o devir-Matraga já está encaminhado, tanto que Augusto diz para Tião da Thereza: "Não tem mais nenhum Nhô Augusto Estêves, das Pindaíbas, Tião..." (ROSA, 2015, p. 315). O personagem é neste momento apenas Nhô Augusto, diferente daquele mesmo homem do início do conto. Agora ele sabe o que deve fazer e até mesmo consegue desviar a tentação para o mal: "abaixou o queixo; e nem adiantou repetir para si mesmo a jaculatória do coração manso e humilde: teve foi de sair, para trás das bananeiras, onde se ajoelhou e rejurou: — P'ra o céu eu vou, nem que seja a porrete!....". (ROSA, 2015, p. 315). O desejo do protagonista de que cheguem sua hora e vez é o que o move e assim, a máquina desejante é também a desfazedora dos rostos de Augusto Matraga.

Com todo esse devir constante, o personagem tenta criar para si um $\mathrm{CsO}$, o que não quer dizer que ele esteja em busca da dor e nem mesmo do prazer pelo sofrimento. Augusto apenas procura para si um $\mathrm{CsO}$ que é constituído pelo sofrimento, assim como afirmam Deleuze e Guatarri sobre o masoquista, cuja relação cabe perfeitamente no caso do protagonista do conto de Guimarães Rosa. (DELEUZE \& GUATARRI, 1996, p. 12).

Mas com tanto sofrimento, Nhô Augusto não consegue desviar a tristeza que o ronda e chega a duvidar de sua redenção. Sua vontade era de voltar e vingar-se de todos, porém, lembrava - se sempre do que o padre tinha lhe dito.

\footnotetext{
Sim, era melhor rezar mais, trabalhar mais e escorar firme, para poder alcançar o reino-do-céu. Mas o mais terrível era que o desmazelo de alma em que se achava não lhe deixava esperança nenhuma do jeito de que o Céu podia ser.

- Desonrado, desmerecido, marcado a ferro feito rês, mãe Quitéria, e assim tão mole, tão sem homência, será que eu posso mesmo entrar no céu?!...

— Não fala fácil, meu filho!... Dei'stá: debaixo do angu tem molho, e atrás de morro tem morro.

- Isso sim... Cada um tem a sua vez, e a minha hora há-de chegar!..." (ROSA, 2015, p. 316).
}

\footnotetext{
${ }^{27}$ Para Deleuze e Guatarri, o desejo se completa nele mesmo e por isso, "o sofrimento do masoquista é o preço que ele deve pagar, não para atingir o prazer, mas para desligar o pseudoliame de desejo com o prazer como medida extrínseca. [...] Em suma, o masoquista serve-se do sofrimento como de um meio para constituir um corpo sem órgãos e depreender um plano de consistência do desejo. Que existam outros meios, outros procedimentos diferentes do masoquismo e certamente melhores é outra questão; o fato é que este procedimento convém a alguns." (DELEUZE \& GUATARRI, 1996, p. 16). Os filósofos defendem que o masoquista não busca a dor, mas um CsO. "O que é certo é que o masoquista fez para si um CsO em tais condições que este, desde então, só pode ser povoado por intensidades de dor, ondas doloríferas. É falso dizer que o masoquista busca a dor, mas não menos falso é dizer que ele busca o prazer de um forma particularmente suspensiva ou desviada. Ele busca um CsO, mas de tal tipo que ele só poderá ser preenchido, percorrido pela dor, em virtude das próprias condições em que foi constituído." (DELEUZE \& GUATARRI, 1996, p. 12).
} 
As ondas de sofrimento pelas quais passa o personagem vão modificando-o cada vez mais, desrostificando-o. O sofrimento de Nhô Augusto faz com que ele perceba o mundo ao seu redor, prestando atenção em paisagens que antes passariam despercebidas por ele. A natureza passa a ter um poder fundamental no ressurgimento do protagonista, fazendo-o acreditar que sua hora chegará.

\footnotetext{
Até que, pouco a pouco, devagarinho, imperceptível, alguma cousa pegou a querer voltar para ele, a crescer-lhe do fundo para fora, sorrateira como a chegada do tempo das águas, que vinha vindo paralela: com o calor dos dias aumentando, e os dias cada vez maiores, e o joão-de-barro construindo casa nova, e as sementinhas, que hibernavam na poeira, esperando na poeira, em misteriosas incubações. Nhô Augusto agora tinha muita fome e muito sono. O trabalho entusiasmava e era leve. Não tinha precisão de enxotar as tristezas. Não pensava nada... E as mariposas e os cupins-de-asas vinham voar ao redor da lamparina... Círculo rodeando a lua cheia, sem se encostar... E começaram os cantos. Primeiro, os sapos: - "Sapo na seca coaxando, chuva beirando", mãe Quitéria!... - Apareceu uma jia na horta, e pererecas dentro de casa, pelas paredes... E os escorpiões e as minhocas pulavam no terreiro, perseguidos pela correição das lava-pés, em préstitos atarefados e compridos... No céu sul, houve nuvens maiores, mais escuras. Aí, o peixe frito pegou a cantar de noite. A casca de lua, de bico para baixo, "despejando"... Um vento frio, no fim do calor do dia... Na orilha do atoleiro, a saracura fêmea gritou, pedindo três potes, três potes, três potes para apanhar água... Choveu. Então, tudo estava mesmo muito mudado, e Nhô Augusto, de repente, pensou com a ideia muito fácil, e o corpo muito bom. Quis se assustar, mas se riu:

— Deus está tirando o saco das minhas costas, mãe Quitéria! Agora eu sei que ele está se lembrando de mim...

— Louvor ao Divino, meu filho!" (ROSA, 2015. p. 317-318).
}

É como se a natureza representasse a primavera da vida do protagonista. O surgimento de novas flores ou de novas esperanças é um sinal de que sua hora estava para chegar. A penitência já não é mais motivo de sofrimento, mas o caminho para a redenção.

Quando Joãozinho Bem-Bem e seu bando chegam ao Povoado do Tombador, Augusto Matraga fica admirado com tais homens, pois eles lembram seu estilo de vida antes da queda do penhasco. Ele se autoidentifica com o grupo e rapidamente os abriga e os alimenta. Oliveira destaca que Augusto, através do bando de Bem-Bem "retorna a si mesmo mas já em devir-Matraga, atualizando-se em inédita conexão com o fora." (OLIVEIRA, 2003, p. 114). Mesmo recebendo o convite do chefe do grupo para integrar-se a eles, Augusto recusa, pois já não é mais o mesmo e sabe que ainda não chegou sua hora.

Ele tem a oportunidade de se vingar do Major Consilva através de seu novo amigo e sua turma, porém, o protagonista é firme em sua decisão de se redimir de seus pecados e mesmo se entusiasmando com a chegada dos jagunços, não cai em tentação.

E só então foi que ele soube de que jeito estava pegado à sua penitência, e entendeu que essa história de se navegar com religião, e de querer tirar sua alma da boca do demônio, era a mesma coisa que entrar num brejão, que, para a frente, para trás e para os lados, é sempre dificultoso e atola sempre mais. (ROSA, 2015, p. 325).

Sua fé fez com que não desanimasse e em uma linda manhã de sol, através de sinais da natureza, Augusto sente que chegou sua hora de partir, e assim como Jesus Cristo, sai em seu jumento, buscando sua hora e vez ou mesmo, a continuação de seu devir-Matraga. Chegando ao povoado do Rala-Coco ele encontra Joãozinho Bem-Bem, 
que o conta sobre a morte de Juruminho, capanga de seu bando que foi morto pelas costas. O assassino fugiu, mas o chefe dos Jagunços promete a desforra da família do matador. Além disso, Augusto é novamente convidado a integrar-se ao grupo, convite que mais uma vez é recusado pelo protagonista. No acampamento de Bem-Bem surge um velho, pai do assassino de Juruminho, que implora ao chefe dos jagunços para que não faça nada à sua família.

\begin{abstract}
- Ai, seu Joãozinho Bem-Bem, então lhe peço, pelo amor da senhora sua mãe, que o teve e lhe deu de mamar, eu lhe peço que dê ordem de matarem só este velho, que não presta para mais nada... Mas que não mande judiar com os pobrezinhos dos meus filhos e minhas filhas, que estão lá em casa sofrendo, adoecendo de medo, e que não têm culpa nenhuma do que fez o irmão... Pelo sangue de Jesus Cristo e pelas lágrimas da Virgem Maria!... (ROSA, 2015, p. 334).
\end{abstract}

Joãozinho Bem-Bem, mesmo vendo o velho ajoelhado implorando que não fizesse nada a sua família, diz não ter como atendê-lo. No entanto, chega a hora e a vez de Augusto Matraga e este se mete na conversa: "- Não faz isso, meu amigo seu Joãozinho Bem-Bem, que o desgraçado do velho está pedindo em nome de Nosso Senhor e da Virgem Maria! E o que vocês estão querendo fazer em casa dele é coisa que nem Deus não manda e nem o diabo não faz!" (ROSA, 2015, p. 335).

Mesmo Nhô Augusto pedindo para que Bem-Bem não fizesse nada contra a família do assassino, o chefe jagunço discorda e ainda acha de mau gosto seu próprio amigo pedir-lhe isto. Vendo que não teria mais jeito, o protagonista diz que então o outro terá de passar por cima de seu cadáver, pois não mais compactua com injustiças. Neste momento é a hora e vez de Matraga, que parte para cima, não se esquecendo de invocar a Deus: "- Epa! Nomopadrofilhospritossantamêin! Avança, cambada de filhos-da mãe, que chegou minha vez!...” (ROSA, 2015, p. 335).

A briga foi intensa e no final restaram só Nhô Augusto e Joãozinho Bem-Bem, para morrerem ali, juntos. Aquele, sem esquecer sua fé, dizia ao outro para que se arrependesse de todo o mal que fez para pode alcançar o céu. Satisfeito com sua hora e vez que enfim chegou, Matraga quer morrer na paz do Senhor: "- P'ra dentro de casa, não, minha gente. Quero me acabar no solto, olhando o céu, e no claro... Quero é que um de vocês chame um padre... Pede para ele vir me abençoando pelo caminho, que senão é capaz de não me achar mais... E riu." (ROSA, 2015, p. 337).

Nhô Augusto, que surgiu naquele arraial com o animalzinho sagrado, reforça seu rosto de santo para toda aquela gente, já que morreu fazendo justiça a uma família. " 'Foi Deus quem mandou esse homem no jumento, por mór de salvar as famílias da gente!..."” (ROSA, 2015, p. 337). O velho também agradecia ao homem que apareceu naquele dia, naquele povoado, para salvar toda a sua família: "— Traz meus filhos, para agradecerem a ele, para beijarem os pés dele!... Não deixem este santo morrer assim..." (ROSA, 2015, p. 337).

Abençoando a filha e dona Dionóra, o protagonista morre contente por ter se cumprido a profecia do padre. "Então, Augusto Matraga fechou um pouco os olhos, com sorriso intenso nos lábios lambuzados de sangue, e de seu rosto subia um sério contentamento." (ROSA, 2015, p. 338).

Mas apesar de ter morrido como um santo para as pessoas que viram a justiça que ele fez, Augusto Matraga não o é, pois compartilha ao mesmo tempo de outro rosto, o do mal, ou seja, ele fez justiça matando outra pessoa ou ainda, fez o bem através do mal. Deste modo, pode-se dizer que em sua hora e vez o protagonista ganha uma nova rostidade, o rosto de Matraga ou devir-Matraga. Aquele que no início do conto "não é Matraga, não é nada." (ROSA, 2015, p. 298); agora sim é alguém, é Matraga, a fusão 
entre o bem e o mal. Seu instinto violento que antes servia apenas para fazer o mal agora é utilizado para fazer o bem.

De acordo com Queiroz (2017), "Catolicismo popular e jagunçagem se misturam no enredo para a composição da transformação existencial gradativa do personagem Nhô Augusto, de homem violento, imoral e egoísta, até conseguir alcançar um novo ethos, cujo clímax é na hora da sua morte." (QUEIROS, 2017, p. 88). Em sua hora e vez não é apenas o Augusto valentão que está ali nem apenas o santo. Sua hora gloriosa é constituída por ambos os rostos ou mesmo, pelo rosto Matraga. Além disso, este nome, discutido no início deste tópico, revela grande relação de sentido entre seu significado e o personagem. Segundo Queiroz:

\begin{abstract}
é um neologismo de matraz, cujo significado etimológico associa-se a um vaso utilizado para operações alquímicas que envolvem transformações elementares e anímicas. Este termo, sendo usado no título para significar metaforicamente o personagem, indica a sua capacidade de atuar como um alquimista de sua própria existência, moldando-a a partir de uma essência de barro, própria a um homem violento, cheio de desejos e vícios carnais, para a construção de uma existência de ouro, elevada espiritualmente, alcançada a partir da penitência, da meditação e do trabalho cujo clímax é o momento de sua "hora e vez". (QUEIROZ, 2017, p. 88).
\end{abstract}

Deste modo, em concordância com o significado de sua alcunha, Matraga é um ser em constante devir, como ocorre na cena de sua morte. Através de seus desejos positivos ele se reconstitui como outro homem, como Matraga, que é o bem e o mal, uma contradição.

Sendo assim, o caráter filosófico de "A hora e a vez de Augusto Matraga" é afirmado. No início da narrativa conhecemos Matraga como aquele que não é nada, pois o verdadeiro Matraga ainda não existia. Através da "pré-morte", por que passa o personagem, este inicia seu devir-Matraga mostrando-nos a face do homem que agora existe.

\title{
3. Considerações finais
}

Deleuze e Guatarri (1995) afirmam que "Não somos mais nós mesmos. Cada um reconhecerá os seus. Fomos ajudados, aspirados, multiplicados." (DELEUZE \& GUATARRI, 1995, p. 11). Sendo assim, não há uma essência que define o indivíduo, uma vez que a cada momento estamos vivenciando novas experiências, desfazendo nosso rosto e nosso organismo.

A multiplicidade de conexões que realizamos através do fora, da linha de fuga, é a qual Augusto Matraga caminha ao resolver desfazer seu rosto e tentar criar para si um CsO. No final, o personagem não é mais o mesmo do início da narrativa, pois ele encaminhou seu devir-Matraga e assim, não é mais Augusto Esteves das Pindaíbas, nem mesmo Nhô Augusto, pois ele se transformou em outro.

Com seu teor filosófico que faz pensar sobre a vida, "A hora e a vez de Augusto Matraga" nos mostra de forma muito radical as mudanças que o indivíduo passa no transcorrer da vida, mesmo que sejam transformações que passam despercebidas. Diante da imensidão do mundo, não há como escapar da contaminação de tudo ao redor.

Pensando no protagonista, o melhor dos destinos é fugir das organizações que nos prendem a tal ponto que bloqueiam as conexões com o mundo externo. Deste mesmo modo, é imprescindível fugir também das rostificações e de um corpo todo 
organizado, cuja tarefa nunca termina. Como diriam Deleuze e Guatarri, o destino do homem é tornar-se oculto. (DELEUZE \& GUATARRI, 1996, p. 36).

Quanto a prosa rosiana em geral, mesmo sendo regionalista ela não se prende a aspectos apenas do sertão. O conto analisado neste estudo é um exemplo da dimensão de temas existenciais abordados por Guimarães Rosa, seja de teor religioso, metafísico ou místico, o que nos possibilitou a realização de uma análise filosófica.

\section{REFERÊNCIAS}

DELEUZE, Gilles \& GUATTARRI, Felix. Introdução: Rizoma. In: Mil Platôs - capitalismo e esquizofrenia. Vol. 1. (Trad. Aurélio Guerra Neto e Celia Pinto Costa). Rio de Janeiro: Editora 34, 1995, p. 11-37.

Como criar para si um Corpo sem Órgãos; Ano Zero -

Rostidades. In:

.Mil Platôs - Capitalismo e Esquizofrenia.

Vol. 3. (Coord. Tradução Ana Lúcia de Oliveira). Rio de Janeiro: Editora 34, 1996, p. 9-61.

ROSA, João Guimarães. A hora e a vez de Augusto Matraga. In: Sagarana. Rio de Janeiro: Nova Fronteira, 2015, p. 265-300.

OLIVEIRA, Silvana. O terceiro estado em Guimarães Rosa: A aventura do devir. 2003. 240 p. Tese (Doutorado em Teoria e história da literatura). UNICAMP, Campinas, 2003. Disponível em: <http://repositorio.unicamp.br/bitstream/REPOSIP/269858/1/Oliveira_Silvana_D.pdf>. Acesso em: 15 dez. 2017.

QUEIROZ, Carlos Eduardo Japiassu de. A Hora e a Vez, no conto "A Hora e a Vez de Augusto Matraga", de Guimarães Rosa. Entheoria: Caderno de Letras e Humanas, Serra Talhada, v. 4, n. 1, p.87-100, dez. 2017. Disponível em: $<$ https://www.usp.br/bibliografia/obra.php?cod=34356\&s=grosa>. Acesso em: 5 jan. 2018. 